\title{
MOTÎFA ŞERTDANÎNÊ DI KILAMÊN DENGÊJAN DE
}

\section{Tekin Çifçi*}

\section{Kurte}

Di nav çanda devki ya kurdan de dengbêjî xwediyê cihekî girîng e. Di van kilaman de evîn û şerên mezin, pirsgirêkên siyasî, civakî û hwd. hatine vegotin. Ew kilam û destanên ku bi hunera dengbêjan bûne bîra civakê, xwediyê gelek taybetiyan e. Yek ji van taybetiyên kilam û destanên kurdî, danîna şertan e. Ango kilam li ser hîmê şertan ava dibe. Bi taybetî em di kilamên dengbêjan yên şer û evîniyê de danîna gelek şertan dibînin. Ji bo xurtkirina naveroka destanê, ceribandina lehengan, berjewendiyên takekesî, ji bo nedana keçikê û hwd. şertên giran li pêşiya leheng têne danîn. Şert, piranî ji aliyê keçik an jî bavê keçikê ve têne danîn. Kesê ku şertan bîne cih jî gelek caran dilketî ye. Hewldanên dilketî, ji aliyekî ve di nav guhdaran de rê li ber kelecanê vedike ji aliyê din ve naveroka kilamê dewlemend dike. Di vê gotarê de mîjara me, di kilamên kurdî yên dengbêjan de danîna hin şertan e. Di vê gotarê de dê hewl bê dayîn da ku rewşa danîna şertan, sedemên wan û encamên wan were.

Peyvên Sereke: Dengbêj, Kurdî, Kilam, Motîf, Şertdanîn

\section{STIPULATION MOTIF IN THE SONGS OF DENGBÊJ}

\begin{abstract}
Dengbejs (Kurdish bards) have a very important place in Kurdish oral culture. Love and great battles, political and social issues are narrated in kilams (ballads). These kilams and epics that have been a part of social memory of the society through artistry have got many unique features. By means of artistry of dengbêj and kilams and epics that take part in the social memory have many unique features. One of the characteristics of the Kurdish kilams and epics is stipulation. Some kilams are recited on stipulation. In dengbêj's ballads especially in those with regard to war and love there are many stipulations. In order to strengthen the content of the epic, the hero came across harsh conditions such as testing character, personal interests, obscure marriage of lovers. These conditions are usually made by the father of the girl or by the daughter herself. The character in love generally fulfill the conditions. In this way, excitement and diversity are created in the epic. This article discusses some forms of stipulation in Kurdish kilams. In this sense, the stipulation and reason and conclusion of them will be explained in this article.
\end{abstract}

Keywords: Dengbêj, Kurdish, Kilam (Kurdish songs), Motiv, Stipulation

Makale Gönderim Tarihi: 31.03.2019, Kabul Tarihi: 30.04.2019

Doi: $10.26791 /$ sarkiat.547257

* Dr, Hacı Hamdiye Özdemir Ortaokulu, Artuklu/Mardin, tekincifci@ gmail.com

ORCID ID: orcid.org/0000-0002-1003-1711 


\section{DESTPÊK}

Çanda devkî, ji çanda civakên ku haya wan ji nivîs û matbaayê tûneye, heger agahdar bin jî nikaribin bi kar bînîn re tê gotin. Ev civak, di jiyana xwe ya rojane de tenê axaftinê û bîra devkî ya dîrokî bi kar tînin. ${ }^{1}$ Çanda devkî, wekî axaftinên rojane, zimanê hilberînê, stran, danûstendin, çîrok, destan, qewlêrk û hwd. di gelek qadên cihêreng de xûya dibe û piştî çanda nivîskî jî hebûna xwe didomîne. Lê belê her ku cihê nivîsê û teknolojiyê pêş dikeve, qada vegotina devkî û jiberkirinê jî teng dibe. Di gelek waran de çanda nivîskî û ya devkî bi hev re têne bikaranîn. Ji bo ku daneyek bibe perçeyek ji folklora civakê, divê teqez di nava pêvajoya çanda devkî de bijî û hebûna xwe bi vî rengî bidomîne. ${ }^{2}$

Di nav metnên nivîskî yên kevin de, daneyên çanda devkî têne dîtin. Wek mînak, em dizanin ku Heredot "Bavê Dîrokê û mirovnasiyê" di berhema xwe de cih daye bûyêr, serhatî û bihîstiyariyên serdema xwe ango tiştê ku ji wî re hatiye gotin nivîsiye. ${ }^{3}$ Wekî gelek civakên din ên dinyayê, di nav civaka Kurdan de jî̀ çanda devkî gelekî dewlemend e. Bi taybetî di warê muzîkê û vegotinê de çanda devkî ya Kurdan gelekî pêşketî ye. Rehên mûzîka kurdî bi giştî digihêjin hunera gel. Mûzîka kurdî, ji aliyê naverok û teşeyê ve bi jiyana rojane ya kurdan ve girêdayî ye. Her tiştê ku di jiyana kurdan ya şênber û razber de cih girtiye bûye mijara mûzîka Kurdî. Ji aliyê teşe, şêwe û derûnî ve mûzîka kurdî xwediyê pirdengî û pirrengiyeke herêmî ye. Erda Kurdistanê ya berfireh û bi çiya, neval, deşt û çemên mezin dagirtî, rê li ber pirsgirêkên ragihandinê yên nav civakê vedike. Lê belê ji aliyê din ve rê li ber dewlemendiya cûre û amûrên muzîkê jî vedike. ${ }^{4}$

Ji qewîmînan heta helbestan; ji çîrokan heya destanan her tişt bi kilamkî tê gotin. Mebest ew e ku çand û serpêhatî bi vê rêbazê bigihêjin nifşên nû jibîr nebe. Kilamên Kurdî yên ku ji aliyê dengbêjan ve têne vegotin, ji mûzîkê bêtir bi peyvê ve girêdayî ne. ${ }^{5}$ Ango di kilaman de "peyv" serdest e. Pîrepayîzok, heyranok, dîlok, lorîk û lawje tenê çend cûreyên ji formen muzîka kurdî ne. Her cûreyek xwediyê hin taybetiyan e. Hin ji van kilamên ku wekî qewlêrk têne penasekirin ji bo zarokan in; kêfa zarokan tînin û wan perwerde dikin. ${ }^{6}$ Di nav van qewlêrkan de ji pesindanê heya rexneyên giran ta tinaz û heqareta li mirovan gelek mînak hene. ${ }^{7}$ Hin kilam hene ku tenê ji bo şahiyan e; ji peyv û wateyê bêtir melodî li pêş e. Ev stran, hest û kelecana dilê beşdarên şahiyan radikin û civakê dixin nav tevgerekê bextewar.

Beşek mezin ji kilamên kurdî, li ser bûyer û qewimînên ku bi salan bandor li ser civakê kirine hatine amadekirin. Di van kilaman de evîn û şerên mezin, pirsgirêkên siyasî û civakî hatine vegotin. Bi taybetî pîrsgirêka evîn û jinê bûye mijara gelek kilaman.

Kilam, bi rêya dengbêjan û çanda dengbêjiyê -wekî kevneşopiyekê- ji serdemên kevin heta roja îro hatine gotin û dê di paşerojê de jî ew rewş bidome.

\footnotetext{
${ }^{1}$ Bozkurt Güvenç, Insan ve Kültür, (İstanbul: Remzi Kitabevi, 1996), 19.

${ }^{2}$ Abidin Parıltı, Dengbêjler Sözün Yazglsı, (İstanbul: İthaki Yayınları, 2006), 18.

${ }^{3}$ Dan Ben Amos, "Folkloru Tanımlamak”, Wer. Dilara Koçbaş, Folklora Doğru Dergisi 64 (2002): 4.

${ }^{4}$ Kendan Nezan, "Kürt Müziği”, Amadekar: Mehmet Bayrak, Kürt Müziği, Dansları ve Şarkıları, weş. Özge, Ankara 2002, c.1, r.52. (51-60).

${ }^{5}$ Mehrard R. Izady, Kürtler, Wer.: Cemal Atilla, Çapa Sêyemin, (İstanbul: Doz Yayınları, 2011), 432.

${ }^{6}$ Nureddîn El-Salihi, "Kürdistan'da Müzik”, Kürt Müziği, Danslarl ve Şarkıları Amadekar: Mehmet Bayrak, (Ankara: Özge Yayınları, 2002), 1: 145.

7 Heciyê Cindî, Emînê Evdal, Folklora Kurmanca, Tîpguhêzî (Ji Kirîlî bo Latînî): Tosinê Reşîd, (İstanbul: Avesta Yayınları, 2008), 493-504.
} 


\section{Dengbêj Kî Ne, Mirov Çawa Dibin Dengbêj?}

Wateya peyva "dengbêj" ya ferhengî "hunermendê deng" e. ${ }^{8}$ Mehmed Uzun, dengbêjan wekî kesên ku "teşe didin deng, deng dibêjin; bîra mirovan zindî dihêlin bi ser de gelek caran bixwe dibin bîr" penase dike. ${ }^{9}$ Parıltı, dengbêjan wekî "Ew vebêjên $\mathrm{ku}$ xwendin û nivîsandina wan tuneye lê belê bi bi nirx û taybetiyên çanda devkî gihane; tevî kevneşopî û nakokiyên wê civaka xwe baş nas dikin; xwediyê bîreke xurt in û çîrok û serhatiyên Kurdan bi hunera dengê xwe û car caran jî bi alîkariya hin amûran ji civakê re pêşkêş dikin.” penase dike. ${ }^{10}$

Di nav Kurdan de kesên ku kilaman distrên ango dibêjin, li gorî herêman -tevî ku hin hûrgilî di navbera wan de hene- bi gelek navan têne binavkirin. Wek mînak, i herêma Semsûrê û Rihayê ji wan kesên ku kilaman (bi taybetî jî kilamên şer, evîn, destan û çîrokî) dibêjin re "Delal" tê gotin. Wek, Delalê Boronegê, Delalê Binê Beriyê û hwd. Canser Kardaş, dibêje ku "Ji dêvila peyva dengbêj, li gorî herêman peyvên wekî "stranbêj”, "kilambêj”, "kilamxan", "qewlikbêj”, "çîrokbêj”, "mitirb/mitirb” û hwd. jî têne bikaranîn."

Piştî pêşketinên di warê teknolojî û amûrên ragihandinê yên wekî televîzyon, radyo, medyaya civakî û berhemên nivîskî di nav kurdan de mirov dikare bibêje ku peyva "dengbêj" berbelav dibe û ji aliyê civakê ve bêtir ev peyv tê tercîhkirin.

Kardaş, di xebata xwe ya ku çanda Kurdan ya dengbêjiyê û çanda Tirkan ya Aşiqiyê berawird kiriye de behsa hin taybetmendiyên dengbêjan dike. Li gorî Kardaş, ji bo ku kesek bibe "denbêjekî baş" divê hin taybetiyan di xwe de bihewîne. Kardaş, van taybetmendiyan bi kurtî dikare weha dabeş dike:

Divê berî her tiştî, mirov xwediyê deng û qirikeke baş be. Ji lewra kesê ku dengê wî "ne xweş" be, nikaribe dengê xwe baş bikar bîne, heke ew kes hunera vegotinê nizanibe, wê nikare bibe dengbêj.

Divê zanibe "ji ber xwe ve" biafirîne û kilamên dengbêjên bi nav û deng jî bizanibe.

Ji nirxên civakê agahdar be û li gorî wan nirxan tevbigere.

Divê mirov xwediyê bîreke xûrt be û karibe gelek kilaman jiber bike û van kilaman di hişê xwe de bihêle. Ji bilî berhemên xwe, divê karibe berhemên dengbêjên din jî baş şîrove bike û bibêje.

Divê, digel devoka xwe ya Kurdî, haya wî ji devokên din ên Kurdî jî hebe.

Lê belê hunera şîrovekirina kilaman jî bikaribe pêk bîne.

Divê ji karê xwe hez bike. Herweha di dema vegotinê de -heta radeyekê- wek şanogerekî tevbigere û bi tevgera dest û rûyê xwe guhdaran bikişîne nav çîrokê. Divê haya wî ji hemû civaka guhdar hebe û li gorî berteka civaka guhdaran pêvajoja vegotina kilamê bidomîne an jî kilamê biqedîne. ${ }^{12}$ Dengbêj jî neçar e ku li gor rûmeta ku civakê daye wî tevbigere. Lewra wekî ku Connerton teorîze kiriye, ew liv û

\footnotetext{
${ }^{8}$ Zana Farqînî, "Dengbêj”, Ferhenga Kurdî-Tirkî, (Stenbol: Weşanên Enstitûya Kurdî ya Stenbolê, 2004), 461.

${ }^{9}$ Mehmed Uzun, Dengbêjlerîm, (İstanbul: İthaki Yayınları, 2006), 12.

${ }^{10}$ Parıltı, Dengbêjler Sözün Yazgısı, 64-65.

${ }^{11}$ Canser Kardaş, "Dengbêjlîk Geleneği”, Kürtler (Toplum, Din), Edit. Adnan Demircan, Celil Abuzar, Metin Bozan, (İstanbul: Nida Yayınları, 2015), 158.

12 Canser Kardaş, Dengbêjlik Geleneği ve Âşık Edebiyatı Ile Karşılaştırılması (Doktora Tezi, Fırat Üniversitesi, 2013), 23-24.
} 
tevgerên ku civak wekî kevneşopiyan pêk tîne, her yek ji wan xwediyê wateyekê ye. Wek mînak, Di kevneşopiya hin çandan de dema ku kesek kete odeyekê, di heman kêliyê de hemû civak radibe ser piya û ji bo ji nû ve rûniştinê li benda destûra kesê ku ketiye hundir dimîne. Ew tevger tê wateya rêzgirtin û pejirandina otorîteya wî kesê ku ketiye hundir. Heger kesek li aliyê herî jor ê civatê, li ser cihekî bilind bi tenê rûne, wateya vê tevgerê diyar e. Ew kes xwe di ser her kesê li civatê rûniştî re dibine. ${ }^{13}$

Kilamên kurdî, li gorî gelek meqaman têne gotin, ev meqam piranî di heman demê de bi lîstika va jî girêdayî ne. Dengbêj, car caran kilamekê bi çend meqaman dibêje. Herweha dikare ji bo kilameke heyî meqamekî nû jî biafirîne. Di vê mijarê de azad e. Lê belê di vegotinê de neçare ku hest, nirx û daxwazên civaka xwe jî raçav bike. Di binavkirina meqamê kilaman de jî pîvaneke zelal tuneye. Car caran navê kesekê/î, navê herêmekê, navê lîstikekê dikare bibe navê meqamê kilamê. Wekî Meqamê Şêxanî, Meqamê Meyremê, Meqamê Dersemê. ${ }^{14}$

\section{Motîfa Şertdanînê}

Motîf, bi wateya xwe ya ferhengî ji kesayet, mijar, tişt, qalib û hwd. ên ku di berhemên wêjeyî de ango di folklorê de cih digrin re tê gotin. Motîf bixwe sembol in, ji wateya xwe ya ferhengî zêdetir in. Ji ber vê yeke hunermend, -çi nivîskar, helbestkar, dengbêj, çi ji qadeke din ya hunerî dibe- di berhema xwe de cih dide hin motîfan. Lewra, motif di nav berhemê de peywireke girîng hildidin ser milên xwe. Ji aliyekî ve bi dubareyan wekî nasnameya berhemê di bîr û hişê hunermend, xwendevan û guhdaran de cih digrin. Ji aliye din ve dibin lehengê berhemê, çîrok li dora van motîfan tê hunandin. Hin motîf hene ku di nav gelek çandan de kêm-zêde hevpar in. Wekî "Keloxlan" ê Tirkan û "Keçel"ê Kurdan; "Cadı" ya Ewropiyan û "Pîra Mer(iv)xwûr" ya kurdan, "çi hebû çi tûnebû", "hûtê heftserî", "teyrê sîmûrg", "rêya çûn û nehatê" û hwd.

Hin motif hene ku di gelek berheman de cih digrin. Wek mînak, motîfa "hesp"ê, motîfa "keçika ku diçe ser kaniyê", "keçika dikeve xewna lawikê jîr" û hwd.

Di kilamên dengbêjan de mirov dikare gelek motîfên rengîn bibîne. Wek "keça Fille û lawikê Misilman", "hesp", "keça piçûk lê rindik", "keça dewlemend û lawikê feqîr", "çil roj û çil şev", "veguhestina gustîlkan", "axa", "beg”, mîr û hwd. Tarduş, di gotara xwe de behsa gelek motif û taybetiyên lehengên kilam û destanên kurdî dike. Wek mînak: Bavê leheng hikimdar/mîr/beg/axa ye; Dê û bavê leheng ne xizmên hev in; Navê bavê lehengî tê gotin lê qala navê dayika lehengî nayê kirin; Serpêhatiya leheng ne li cî û warê çêbûna wî diqewime; Leheng xwedî hespekî navdar e; Destebirayekî wî heye û hwd. ${ }^{15}$ Yek ji van motîfên girîng di kilamên kurdî de, "danîna şertan" ango "qewl" e. Ango kilam li ser hîmê şertan ava dibe. Li jêr dê hewl bê dayîn ku motîfa şertdanînê û qewldanê tevî hin mînakan were nirxandin.

Di jiyana rojane û pêvajoya zewacê ya asayî de ji bo ku zewac pêk were, hin şert û merc kêm-zêde dertê pêşiya her mêrî. Hin malbat hene ku beriya dayîna keça xwe qelen, zêr, çek an jî kirîna alavên malê yên wekî firraq, xalîçe, livîn û hwd. wekî şert datînin ber malbata zava. Lê hin şertên gelekî giran jî hene ku sedemên wan yên taybet hene. Wekî kuştina hin mêran, revandina hin kesan, anîna talanan, revandina hespan

\footnotetext{
${ }^{13}$ Paul Connerton, Toplumlar Nasıl Anımsar? Wergera Ji Îngilizî: Alâeddin Şenel, (İstanbul: Ayrıntı Yayınlar1, 1992), 116.

${ }^{14}$ Christian Poche, "Kürt Müziğii”, Kürt Müziği, Danslarl ve Şarkıları, Haz. Mehmet Bayrak, (Ankara: Özge Yayınlar1, 2002) 1: 126.

15 İbrahim Tarduş, "Taybetiyên Lehengên Tradîsyonel di Vegotina Kurdî de", The Journal of Mesopotamian Studies, 3/1, (Winter 2018), 57-76.
} 
û hwd. Carinan ev şertên giran, dibin sedema afirandina destan û kilaman. Lewra pêvajo û encamên bicihanîna wan şertan gelek caran dibin sedema trajediyên gelekî mezin. Bi taybetî em di kilamên dengbêjan yên şeran û evînan de danîna gelek şertên bi vî rengî dibînin. Şert ji aliyê keçik an jî bavê keçikê ve têne danîn. Kesê ku van şertan bîne cih jî gelek caran dilketî ye. Di vê pêvajoyê de hin dost û nasên dilketî jî alîkariya wî dikin. Digel ku ev kilam piranî wekî çîrokên evînên qurmiçî têne nîşandan jî di naveroka xwe de helwestên siyasî, raperînên li dijî serdestan, gazinên ji pergalê, şerê di navbera kom, malbat, êl, eşîr û civakan, dewletan û hwd. jî dihewînin. Ji vî aliyî ve dikare bê gotin ku kilam "bertekên li dijî zordestiyê" ne. Ev kilamên ku helwestên siyasî nîşan didin wekî "kilamên protest (kilamên serhildanê)" tê binavkirin. ${ }^{16}$

Gelek aliyên girîng yên şertdanînê em dikarin bijmêrin. Hin ji wan bi hewldana dengbêjî ve girêdayî ne. Dengbêj bi taybetî li ser van şertan disekine. Lê gelek kilam jî hîmê xwe ji çîroka danîna şertan û pêvajoya pêkanîna van şertan datînin. Dengbêj, ji bo ku girîngiya van şertan di bîra guhdaran de bihêle, carinan wan dubare dibêje.

\subsection{Ji Aliyê Civakî ve Danîna Şertan û Hewldanên Bicihanîna Wan}

387ave387 ku şert pêk bên, gelek caran pêdivî bi mûcîzeyan heye. Ev jî tempoya kilamê bilind dike û daxwazeke mezin ya guhdarîkirinê di nava guhdaran de peyda dike. Guhdar, tiştên ku hêza wan têrê nake, ji leheng hêvî dikin. Bi xwe jî carinan bi olanan piştgiriyê didin dengbêj. Dengbêj heya ji wan tê, şert û mercên giran ku li pêşiya leheng hatine danîn, bi dubarekirinê dixin bîra guhdar. Bi vî awayî 387ave387n mêranî û qenciyê di nava civatê de ava dikin. Dengbêj jî di vê pêvajoya dirêj de derfeta pêşkêşkirina hunera xwe bi destên xwe ava dike. ${ }^{17} \mathrm{Li}$ aliyê din ve, 387 ave $387 \mathrm{n}$ wekî dad, mêrxasî û qenciyê di nava civatê de ava dikin. Dengbêj jî di vê pêvajoya dirêj de derfeta pêşkêşkirina hunera xwe dibînin. Ji ber ku kilam devkî ne ango ne nivîskî ne her dengbêj li gorî zanîn û xûrtbûna bîra xwe, li gorî hêza xwe ya jiberkirinê, baweriyên civakê û demê kilam-çîrokê ji nû ve avadikin û vedibêjin. Ev yek jî rê li ber şaxên (waryant) nû yên kilaman vedike. Sîyasetmedar û lêkolînerê Frensî Roger Lescot ku di salên 1930an û pê ve tevî Celadet Elî Bedirxan li ser zimanê Kurdî xebitiye, 387ave387 berhevkirina destana Memê Alan behsa guhdarîkirina bîst dengbêjan dike. ${ }^{18}$

Bi giştî hunera devkî, bi taybetî jî edebiyata devkî -çi kilam, çi çîrok û meselok, çi jî tiştanok û gotinên pêşiya dibin- di nav qada gel ya fỉreh de dijî. ${ }^{19}$ Ev huner bi destê hunermendan xurt dibe. Strandina kilaman jî cûreyek ji edebiyata devkî ye. Bi taybetî di kilaman de hunermend 387ave387 ku bandora kilamê ya li ser guhdaran zêde bike û bala wan her li ser kilamê bihêle, serî li gelek rêbazan dide.

Yek ji van rêbazan jî hûnandina çîrokê ya li derdora hewldanên bicihanîna şertan e. Dengbêj, vê yekê jî bi girêdana gelek çîrok û serpêhatiyên piçûk yên bi hev ve girêdayî pêk 387ave. Dengbêj (û di heman demê de çîrokbêj) berê lehengê xwe dide bi zanetî dide ser rêyên dirêj û dijwar. Ew rê, piranî rêyên "çûn û nehatinê" ne. Sedemên vê rêwitiyê cihêreng in. Wek mînak di gelek çîrokên Kurdî de leheng hewl didin ku herin

\footnotetext{
${ }^{16}$ Salîhî, “Kürdistan'da Müzik”, 147.

${ }^{17}$ Tekin Çifçi, Kilam û Jin, (İstanbul: Nûbihar Yayınları, 2014), 93.

${ }^{18}$ Roger Lescot, "Memê Alan”, Aşiret ve İsyan: Batı’nın Kürt Algısı, Çev. Nuri Fırat, (İstanbul: Avesta Yayınlar1, 2010), 131-132.

19 Yuri M. Sokolov, Folklor: Tarih ve Kuram, wer. Yetke Özer, (Ankara: Geleneksel Yayınları, 2009), 14.
} 
devereke dûr û keçika axa û mîr an jî padîşah ji destê hûtan xelas bikin. Carinan jî li dermanan digerin. Lehengên gelek çîrokan piranî mêr in lê lehengên jin yên weke "Gulcanê" jî hene. ${ }^{20}$

Çeka dengbêj, dengê wî ye. Ew, dengê xwe li gor pêvajoya çîrok-kilamê bilind û nizm dikin. Carinan navberê didin kilamê û beşek ji kilamê wekî çîrokê vedibêjin. Kilama Metran Îsa, ku li herêma Serhedê gelekî navdar e, mînaka vê yekê ye. Salihê Beynatî berî ku dest bi kilamê bike, bi kurtahî behsa çîroka jiyana Meyrema File, Eliyê Qolaxasî û Waliyê Wanê dike. Piştî ku bala guhdaran dikişîne ser çîrokê îcar dest bi kilamê dike û çîrokê bi awayê kilamkî didomîne. Dengbêj wisa dike ku ji 388ave kilamê heta dawiya wê guhê guhdaran li wî ye. ${ }^{21}$ Di vê kilamê de jî şert hene. Heger ku Metran, Meyremê û Elî radestî Waliyê Wanê bike, Walî ew ê hezar kîs pere bide Metran. Piştî ku Waliyê Wanê, bersiveke neyînî ji Metran 388ave388ne, vê 388ave pêşniyareke din dide ber Metran: Tenê 388 ave388 radestkirina Meyrema File, hezar û heftsed kîs pêşniyar dike. Mihemed Arifê Cizrawî vê bûyerê weha şîrove dike:

“....

Waliyê Wanê hatî gazî kiriyê, gotî:

Metrano, dîsa lo lo sed caran li min dîsa, şevê din Min ê di xewna xwe da dîtiye cotekî kevoka firî Tev bezîne, hatine li cem te lîs e

Heke tu mêrî Meryema File, Eliyê Qoleaxasî teslîmî min bikî Ez ê bidim te vî hesabê hezar kîs e

Heke tu qebîl dikî, qebîl nakî bes Meyrema File teslîmî min bike Ez ê bidim te hesabê lo lo Metrano, hezar û heftsed kîs e...."22

Dengbêj, bi deng û gotinên xwe helwesta xwe ya li dijî bêdadiyê eşkere dike û wisa dibe ku guhdar xwe nade aliyê Waliyê misilman. 388ave388 parastina heqiyê xwe dide aliyê Metran Îsa û herweha Meyrema File û Elî. Lewra li gorî dengbêj, Elî û Meyrem du kevok in û Dêra Ixtimarê jî ji xwe re kirine lîs da ku ji xezeba waliyê zalim yê Wanê xwe biparêzin. Dengbêj bi van gotinên xwe taybetiyeke çanda Kurdan derdixe pêş. Lewra Kurd, dema ku keçikekê direvînin xwe davêjin pişt kesekî axa, wêrek û bi dad. Ew jî̀ nîşana bandora hunermendan bi taybetî jî dengbêjan ya li ser berdewamkirina kevneşopiyan e.

Di destana Zembîlfiroş û Gulxatûn de jî şert derdikevin pêş. Gulxatûn 388ave388 ku Zembîlfiroş bike wezîrê 388ave xwe, 388ave Farqînê, şertê ku ew "bê û li ser doşega mîr 388ave" datîne ber Zembîlfiroş. Zembîlfiroş li dîjî vê pêşniyara derveyî ol û 388ave388 civakê derdikeve. Dengbêj bi vî rengî dixwaze ku 388ave di navbera nefsa mirov û aqilê mirov de bîne ber guhdaran da ku mirov li pey nefsa xwe neçin. Di vê 388ave388ne de motîfa helaliyê û paqijiyê gelekî xurt e. ${ }^{23}$ Herweha dengbêj bi hûnera xwe civakê wisa amade dike ku çi kes nikare Gûlxatûnê jber wan daxwazên wê yên "ne li rê" tewanbar nake. Dengbêj, bi vî rengî tevger û pêşniyara Gulxatûnê di 388ave civakê de mehkûm dike û helwesta Zembîlfiroş jî xelat dike; hêjayî pesindanê dibîne.

\footnotetext{
${ }^{20}$ Mehmet Öncü, Çîrokên Efsaneŷ̂ yên Kurdan, (İstanbul: Nûbihar Yayınları, 2014), 325-330.

${ }^{21}$ Çifçi, Kilam û Jin, 125-127.

${ }^{22}$ M. Arif Cizrawî-Hesen Cizrawî, "Metran Îsa", https://www.youtube.com/watch?v=V4tpCfsA7Zg Deşifrekirin: Tekin Çifçi.

${ }^{23}$ Aziz Samur, Destana Zembîlfiroş û Gulxatûn, (İstanbul: Nûbihar Yayınları, 2015), 136.
} 


\subsection{Ji Bo Xurtkirina Naveroka Kilamê Danîna Şertan}

Şertên ku li ber leheng hatine danîn çiqas dijwar û zehmet bin kilam an jî çîrok ewqas xurt dibin. Ji bo leheng bicihanîna şertan êdî dibe pîvana rûmetê. Serdest (Axa, mîr, beg û hwd.) li gor kevneşopiya berê, ji bo ku rûmeta neyarên xwe li erdê bixin, leheng/an dişînin pey talanan. Ew talan piranî ji bo pez û dewaran dibin. Carinan jî wekî destdanîna ser barê karwanên bazirganan pêk tên. Talan, ji bo yê ku talan kiriye pîvana mêrxasiyê (digel ku gelek caran ji talanê sax venagere jî) ye lê ji bo yê ku hatiye talankirin jî şermeke mezin e. Wek ku li jor jî behsa wê hate kirin, revandina hespan talana herî mezin e. Beg, axa û malmezinên herêma rojhilat, bi taybetî jî yên rojhilata navîn, bi jêhatibûna hespên xwe pesnên xwe didin. Heta ku ji wan tê zorê li hespên xwe nakin. Hespên xwe yên cins di tewlê de xwedî dikin. Ji bo ku kesek hespê wan nerevîne lingên wan qeyd dikin û mifteyê jî li cem xwe dihêlin. ${ }^{24}$ Leheng jî ji bo ku bigihêjin "mirazê" xwe divê hespê ku baş tê parastin birevînin. Lehengên kilaman, carinan ji bo ku karibin hespekî bidizin, bi salan ji axa, beg û mîran re şivantiyê, xulamtiyê dikin. Bi vî rengî xwe nêzikî axê dikin da ku karibin cihê hespê bizanin, mifteya qeyda hespê bi dest bixin û plana xwe bi cih bînin.

Carinan jî leheng ji bo dîtina keçika malê bi salan ji axayan re xulamtî û şivantiyê dikin. Wek mînak, dengbêj Fadilê Kufragî dema kilama Fatima Salih Axa dirêse berê lehengê kilamê Ehmed Axa dide ser rêya Rewanduzê û wî dike şivanê Salih Axayê bavê Fatimayê. Ew şivantî şeş sal û neh mehan diajo. Heta ku Fatima ji hungilîska wî fêm dike ku Mihemed ne yekî feqîr û belengaz e. Têdigihê ku Mihemed ji bo dîtîna Fatimayê şivantiyê dike. ${ }^{25}$ Di kilam û çîrokên şivantiyê de heta kêliya dawî îtaat heye. Lê di kilamên ku mijar li ser revandina hespê ava dibe de gelek caran mêrxasiya eşkere heye. Di hin kilaman de jî leheng, ji bo revandina hespan serî li gelek dek û dolaban didin. Ji bo ku kelecana guhdaran li asta bilind be, dengbêj heta ku ji destê wî bê wî hespî weke gencîneyekê vedişêrin. Pirî caran jî ji bo afirandina derfeta revandina hespê leheng cilên xwe diguherînin, xwe dikin dilkê şivan û derwêş û feqîran. Dengbêj baş dizanin ku piştî qefaltina hespê destan berjêr dibe. Kelecan û miraqa guhdaran kêm dibe.

\subsection{Bi Hinceta Tolhildanê û Destnîşankirina Mêrxasiyê Danîna Şertan}

Bi danîna van şert û mercên giran keçik û dê û bavên wê dixwazin ku namzetê zava biceribînin. Başî, qencî, dilsozî û mêrxasiya wî bi çavên xwe bibînin û tirs û xofê bixin nav dilê "neyaran." Ew rêbaz di gelek çîrok û destanên gelên din de jî xuya dibe. Di kilama Dewrêşê Evdî de, heger kesê ku fîncana qehwê rake dive ji bo eşîra Milî here eniya şer û Gêsan û Tirkan re şer bike. Xelata vî şerî jî zewaca bi Edûlê re ye. Bi taybetî di kilamên şeran de dengbêj li ser taybetiyên hespan disekinin û pesnê hespên lehengan didin. Lewre ew dizanin ku hespekî baş dikare di şer de xwediyê xwe serkeftî bike. Hespê nebaş xwediyê xwe dibe mirinê. Lewma jî di gelek destan û kilamên kurdî de revandina hespekî çê an jî caniyekê, dibe mijara şertdanînê. Em dikarin destanên Binevşa Narîn û Cembeliyê Kurê Mîrê Hekarê ${ }^{26}$ de jî vê yekê bibînin Lewre hespekî baş ji bo xwediyê wê nîşana hêz, dewlemendî û pesindanê ye. Ji aliyê din ve jî hesp, "rûmet û namûs" e. Ew kesê ku hespê wî bê dizîn, di nav civatê de dikeve nav şermê. Lewma jî mîr û dewlemendên kurdan ji bo parastina hespê xwe

${ }^{24}$ Mela Mehmûdê Bayezîdî, Adat $\hat{u}$ Rusûmatnameê Ekradiye, Amadekar: Jan Dost, Çapa Duyem (İstanbul: Nûbihar Yayınları, 2012), 64.

${ }^{25}$ Fadilê Kufragî, Destan û Çîrokên Kurdî, Berhevkar: Hogir Berbir, (Diyarbekir: Weşanên Enstitûya Kurdî ya Amedê, 2007), 212-213.

${ }^{26}$ İhsan Colemêrgî, Cembelî (Kurê Mîrê Hekarê), (İstanbul: Avesta Yayınları, 2001). 
xûlam peywirdar kirine. Heger digel hemû tevdîrên parastinê jî hesp were dizîn, ew dê bibe sedema şerê nav eşîr û malbatan.

Di varyanteke kilama Kerr û Kulik de; Elî Emer Axa, ji Kulik ra dibêje: "Bizanibe, $k \hat{\imath}$ fincanê bixwe, here Bêcanê bîne; bê Perîşana qîza min bistîne.” Lewra, Hesê Sadiqê Gêsî, keys lê dîtiye û bi dek û dolaban li ser textê bavê Kerro û Kulik rûniştiye. Kerro û Kulik bi hinceta hilanîna tola bavê xwe û sitendina textê bavê xwe revandina Bêcanê ji xwe re dikin armanc. Heger bi ser bikevin ew ê him text û milkê bavê xwe ji Hesê Sadiqê Gêsî bistînin him jî Kulik ê keça Elî Emer Axa Perîşanê ji xwe re bike kevanî. Piştî şerekî giran Kulik tê kuştin lê belê diya wan -Werdekê- diçe bûka xwe tîne li Kerro -birayê Kulik- mar dike. ${ }^{27}$

\subsection{Danîna Hin Şertan Ya Ji Bo Berjewendiyên Şexsî û Siyasî}

Di bin vê xalê de gelek pirsgirêkên civakî, aborî û siyasî hene. Di hin kilaman de axa û beg dayîn û zewaca keça xwe, ji bo armancên xwe yên siyasî û xurtkirina desthilatiya xwe bi kar tînin. Yek ji van mînakan kilama Dewrêşê Evdî ye. Ev kilam, di eslê xwe de şerê di navbera eşîrên Kurdan (di serî de jî eşîra Milan) û hêzên Osmanî ku ji eşîra Gêsî ya Tirkman, eşîrên Ereb yên Teyî û Şemmeran pêk hatiye vedibêje. ${ }^{28}$ Lê belê di nav dengbêjan de ev bûyer û kilam, li dora evîna Dewrêşê Evdî û Edûlê hatiye hûnandin. Îbrahîm Paşayê Milî, dema ku bi evîna keçika xwe Edûlê û Derwêşê Evdî yê Şerqî (Êzdî) dihise li dijî zewaca wan derdikeve û Êzdî ji ber tirsa êrişên Îbrahîm Paşa direvin Şengalê. Lê belê dema ku Îbrahîm Paşa dikeve tengasiyê bi şertê ku Derwêş û mêrxasên din ên Êzdiyan ji bo wî şer bikin wan efû dike. Li gor şertê ku hatiye danîn, heger ku Derwêş fîncana qehwê ku di nav civatê de digere hilde here şer, ji şerê li dijî Gêsan û Tirkan sax vegere Îbrahîm Paşa jî ew ê destûra zewaca Edûlê û Derwêş bide. ${ }^{29}$

Di varyaneke din ya kilama Kerr û Kulik de, Emer Axa zelfekî ${ }^{30}$ zêr tije şerbet dike û dibêje, "Heçî yê ku ji vê şerbetê vexwe û here hespê Mîrê Ereban

-Bîlîcanê- ji min re bîne ez ê keça xwe -Perîşanê- bidim wî." ${ }^{31}$ Lewre Bilîcan ne hespekî ji rêzê ye. Lê belê mebest ne revandina hespê ye. Mebest şandina hin lehengan ya ser êla Ereban û şikandina hêza wan ya şer e. Bilîcan (hespê Mîrê Ereban) wekî hincetekê ye, lê belê hinceteke xweş e. Heger ku Kerro û Kulik bi ser bikevin axa hem wê bi bibe xwediyê zavayekî mêrxas hem jî wê bibe mezinê herêma xwe. Heger mêrxas têk biçin, axa dikare vê mijarê wekî karekî ji rêzê yê diziyê nîşan bide, destê xwe ji meseleyê bişo. Ji aliyê din ve jî ew ê ji du mêrxasên ku "sibê dikarin serê axa biêşînin" xelas bibe. Helbet leheng jî bi vê yekê dizanin lê pêdiviya wan ya bi xwepesinandinê heye. Feqîr in, tenê bi hêza xwe ya şervaniyê dikarin hebûna xwe biparêzin.

Carinan jî wekî Derwêş û Edûlê baweriya wan cûda ye. Heger ku leheng ji kesên ji rêzê be, bi gumana mezin dê civak jî li dijî vê zewacê derbikeve. Lewra di nav civaka Kurdan de zewaca bi kesên ne misilman re wekî "şermekê" tê pejirandin.

Bi kurtasî dengbêj bi zanetî hemû nakokiyan (helbet ew nakokî jî rastiya civakê ne.) tîne ber hev û ji wan nakokiyan sûdê werdigre. Ew nakokî dikarin çîrokê xûrt bikin û

\footnotetext{
${ }^{27}$ Cindî û Evdal, Folklora Kurmanca. 109-113.

${ }^{28}$ Eyup Kiran, "Mîrêmîran Îbrahîm Paşayê Milî", Kovara Bîr, j. 8 (Zivistan 2008): 70-80.

${ }^{29}$ Osman Îbrahîm, Evîna Mêrxasekî, (Dîyarbekir: Weşanên Lîs, 2008).

${ }^{30}$ Zelf: Qedeha ji sifir.

${ }^{31}$ Cindî, Evdal, Folklora Kurmanca, 148.
} 
peyameke baş bidin civata guhdaran. Bi vî aliyî ve mirov dikare bibêje ku çîrok û kilamên bi vî rengî civakê perwerde dikin. Divê dengbêj bi hostatiya mamosteyekî bala guhdaran bide ser kilamê. Ew yek jî bi xurtkirina lehengan dibe. Wek mînak di kilama Kero û Kulik de, diya wan wisa pesnê hespê Mîrê Ereban dide ku taya wî hespî nehatiye ser rûyê erdê:

"Lawo, go. Hespêd xalê we serê wane hudunin, Guhê wane kêwrîşkî ne,

Navê wan, navtejî ne,

Go, lawo, simê wane simkodîn e..., 32

Heger ku Emer axa bibe xwediyê Bilîcanê, carek din nekeve destê Mîrê Ereban, ew baş dizane ku careke din êla Ereban nikare li herêmê bibe xwediyê statûyeke bilind.

Ji hin kilaman em têdigihên ku axa û beg dema ku li dijî zewacê bin, ji aliyekî ve naxwazin ku dilê keçikên xwe bihêlin ji aliyê din ve jî dixwazin ku ji bêgaviya dilketî sûdê wergirin. Bi gotineke din axa, diketiyan dişînin ser "rêya çûn û nehatinê."3332 Di vartyanteke kilama Derwêşê Evdî ku ji aliyê Celîlê Celîl ve hatiye berhevkirin de Edûlê, ji bo ku bavê xwe ji tengahiyê xelas bike mehra bi xwe re ango namûsa xwe tîne rojevê. Heçî kesê ku ji bo bavê wê here şer, ew ê bi Edûlê re bizewice:

“....

Zor Temir Paşa mektûbê dixwîne, Fîncana

qehwê li ser destê Edûlê datîne,

Edûlê û fincana qahwê li ser tepsîka zêrîn datîne, Li nava dîwana Kîka û Mila digerîne,

Heçî kesê fincana qahwê ji ser destê min hilîne Ewê min mar ke, ê heyfa bavê min hilîne...."34

Wekî ku ji kilama Derwêşê Evdî jî tê fêmkirin, kesê mêrxas -di vê destanê de Derwêşji bo ku bigihêjin mirazê xwe divê mêrxasiya xwe pesend bike û here şer. Ji aliyê din ve Edûlê jî û temir Paşa jî dizanin ku tenê kesên dildar dikarin mirinê bidin ber çavên xwe. Edûlê dizane ku Derwêş diçe mirinê, pir li ber wî dikeve û naxwaze ku ji bo bavê wê here şer. Lê belê ew jî dizane ku divê Derwêş şertê xwe bîne cih yan na nikare li wî welatî bisekine. Civaka kurdan, kesên ku li ser soza xwe nasekinin di nava xwe de nahewîne.

\subsection{Bi “Qewlê Nedanê"” Danîna Şertan}

Di hin kilam û çîrokên kurdî de dema ku bavê keçikê naxwaze keça xwe bide kesekî ji statûya xwe kêmtir, şertên ku pêkhatina wan ne guncav e datîne ber dilketî. Bi vî awayî dixwaze ku lawik dev ji keçika wî berde. Di destana Ferhat û Şîrîn de mîr, qûlkirina çiya û anîna avê ji Ferhat dixwaze. Di çîroka "Lûr de lûr" de dilê keça Axê (Zelxê), dikeve şivanê malê Heso. Heso jî ji Zelxê pir hez dike. Lê belê bavê Zelxê naxwaze ku keçika xwe bide şivanekî. Lewma jî şertên giran datîne ber Heso. Heso hemûyan bi cih tîne. Axa dibîne ku rê namîne, wek şertê dawî silimeke (derence) bilind çêdike, lingekî wê silimê jî sist dihêle. Ji bo ku dema ku pezî pê lê kir bişikê û

\footnotetext{
${ }^{32}$ Cindî, Evdal, Folklora Kurmanca, 149

${ }^{33}$ Ömer Uluçay, Derwêşê Evdî Destanı, (İstanbul: Do Yayınları, 2006), 59.

${ }^{34}$ Celîlê Celîl, Ordîxanê Celîl, Zargotina Kurda, c. 1, (Moscow: Weşanên Nauka, 1978), 177-189.
} 
pê re were xwarê. Silimê dibe li nêzika çem datîne. Paşê bang li Heso dike. Jê re weha dibêje: "Heso, tuyê herî li ser pêlika jor bisekinî û li bilûra xwe bidî. Pez jî ê xwêkirî be. Heke tu karibî mîha yek bi yek hildî ba xwe, ez ê Zelxê bidime te." Hesen dest pê dike û li bilûrê dide. Zelxê dibîne ku her ku pezek pê li lingê silimê yê şikestî dike, dikeve xwarê. Bi dek û dolaba bavê xwe dihise. Li ser vê yekê bang li Heso dike: "...

Lo lo şivanê Çemê Reş,

Şivanê ku deng ji kevir û kuçikan tîne, Te çawa ji Axê bawer kir." 35

Li ser van gotinên Zelxê, Heso jî bi fena Axê dihise. Ew û Zelxê bi hev re xwe ji neqebê davêjin xwarê. Wekî ku di vê çîrok/kilamê de jî xuya dibe, danîna şertên giran her gav rê li ber trajediyan vekiriye.

\section{ENCAM}

Kilamên Kurdî digel ku di sedsala dawî de ji aliyê hin nivîskar, lêkolîner û berhevkaran ve hatine berhevkirin, di nav gel de piranî bi rêya dengbêjan û çîrokbêjan hebûna xwe wekî çanda devkî jî domandine. Gelek ji wan kilaman li ser hîmê bûyerên dîrokî hatine avakirin. Bi alîkariya dengbêjan şêweyeke hunerî û edebî wergirtine û ji aliyê gel ve bi dilsozî hatine guhdarîkirin.

Di kilamên kurdî de gelek motîfên cûda hatine bikaranîn. Bi taybetî di kilamên şer, evîn û destanan de motîfên hesp, axa, revandina hespan û talana pezan, keça axa-beg ya xweşik û xortê feqîr lê mêrxas pir hatine bikaranîn. Bûyer gelek caran li dora evîna keça mîr-beg-axa û xortê wêrek, şervan û qeşeng diqewimin. Ew bûyer jî bi danîna hin şertên giran li ber xortê leheng yên ji aliyê "axa-beg-mîrê" zalim dest pê dikin. Ji aliyê teşe û hunerî ve danîna hin şertên giran yên li ber leheng, di nav guhdaran de rê li ber kelecanê vedike. Dengbêj vî rengî di nav guhdaran û lehengên kilamê de -bihemdî an jî bêhemdî- têkiliyeke hestiyarî saz dike. Leheng/an ji bo gel dike mînakeke baş û hewl dide ku guhdar wan kesan ji xwe re wekî mînakên baş bibîne. Hestên wekî hêrs, evîn, wekhevî, dijberî, bêdadî û hwd. bi alîkariya van kilaman wekî nirxên civakî bi cih dibin. Dengbêj, di nav guhdaran de, ji bo leheng hestên "baş" û li dijî bêdadiyê û kesên "nebaş" jî hêrseke mezin saz dike. Ev kilamên bi vî rengî têkiliyên nav-civakî saz dikin û bi vî rengî çand û nirxên civakê ji nifşekî derbasî nifşê din dibin.

Ji aliyê wateyê ve motîfa danîna şertan ya li ber lehengan, dibin mînakên nasîna dîroka gel û têkiliyên di navbera gel de. Digel ku hin bûyerên derasayî pêk tên û hin mûbalaxa ango zêdekirin li bûyeran çêdibin jî guhdar bi hişmendî tev digere û van bûyeran ji hev derdixe. Hestên netewî, civakî û hebandina malbat, êl û eşînan bi alîkariya van kilaman ji nû ve vedijin. Heger mirov rejeya (rêjeya) xwendin û nivîsandinê ya kêm û tunebûna amûrên ragihandinê yên teknolojîk ên di demên berê de bide ber çavan, mirov dikare dengbêjan wekî nûçegihanan û bûyerên ku vedibêjin jî wekî serhatiyên civakê binirxîne. Dengbêj, bi hunera xwe ji aliyekî ve bûyerên dîrokî û evînên qurmiçî wekî fîlmekê li ber çavên guhdaran zindî dike ji aliyê din ve jî nirx û kevneşopiyên civakê -qenc-xirab bi hev re- li ber çavan radixe.

\footnotetext{
${ }^{35}$ Vrtanes Papazyan, "Lûr De Lûr”, Tîroj, 45 (2010), 58-60.
} 


\section{ÇAVKANî}

Amos, Dan Ben. "Folkloru Tanımlamak”, Wer. Dilara Koçbaş, Folklora Doğru 64, (2002):1-18.

Bayezîdî, Mela Mehmûdê. Adat û Rusûmatnameê Ekradiye. Amadekar: Jan Dost, Çapa Duyem. İstanbul: Nûbihar Yayınları, 2012.

Celîl, Celîlê, Celîl, Ordîxanê. Zargotina Kurda, c. 1, Moscow: Weşanên Nauka, 1978.

Cindî, Heciyê, Evdal, Emînê. Folklora Kurmanca, Tîpguhêzî (Ji Kirîlî bo Latînî):

Tosinê Reşîd, İstanbul: Avesta Yayınları, 2008.

Cizrawî- M. Arif, Cizrawî, Hesen. "Metran Îsa", https://www.youtube.com/watch?v=V4tpCfsA7Zg Deşîfrekirin: Tekin Çifçi.

Colemêrgî, İhsan. Cembelî (Kurê Mîrê Hekarê). İstanbul: Avesta Yayınları, 2001.

Connerton, Paul. Toplumlar Nasıl Anımsar? Wergera Ji Îngilizî: Alâeddin Şenel. İstanbul: Ayrıntı Yayınları, 1992.

Çifçi, Tekin. Kilam û Jin. İstanbul: Nûbihar Yayınları, 2014.

El-Salihi, Nureddîn. “Kürdistan'da Müzik”, Kürt Müziği, Danslart ve Şarkıları, Amadekar: Mehmet Bayrak, Ankara: Özge Yayınları, 2002.

Farqînî, Zana. "Dengbêj”, Ferhenga Kurdî-Tirkî, (Stenbol: Weşanên Enstitûya Kurdî ya Stenbolê, 2004), 461.

Güvenç, Bozkurt. Insan ve Kültür, İstanbul: Remzi Kitabevi, 1996.

Izady, Mehrard R. Kürtler, Wer.: Cemal Atilla, Çapa Sêyemin. İstanbul: Doz Yayinlar1, 2011.

Kardaş, Canser. "Dengbêjlî̂k Geleneği”. Kürtler (Toplum, Din). Edt. Adnan Demircan, Adnan, Celil, Abuzar, Bozan, Metin. 2: 157-171. İstanbul: Nida Yayınları, 2015.

Kardaş, Canser. Dengbêjlik Geleneği ve Âşık Edebiyatı İle Karşılaştırılması. Doktora Tezi, Frrat Üniversitesi, 2013.

Kiran, Eyup. "Mîrêmîran Îbrahîm Paşayê Milı̂”. Kovara Bîr, j. 8 (Zivistan 2008): 7080.

Kufragî, Fadilê. Destan û Çîrokên Kurdî. Berhevkar: Hogir Berbir. Diyarbekir: Weşanên Enstitûya Kurdî ya Amedê, 2007.

Lescot, Roger. "Memê Alan”, Aşiret ve İsyan: Batı'nın Kürt Algısı. Çev. Nuri Firat. İstanbul: Avesta Yayınları, 2010.

Nezan, Kendal. "Kürt Müziğii”. Amadekar: Mehmet Bayrak, Kürt Müziği, Dansları ve Şarkıları. 1: 51-64. Ankara: Özge Yayınları, 2002.

Öncü, Mehmet. Çîrokên Efsaneyî Yên Kurdan. İstanbul: Nûbihar Yayınları, 2014. Papazyan, Vrtanes. "Lûr De Lûr". Tîroj 45 (2010), 58-60.

Osman, Îbrahîm. Evîna Mêrxasekî. Dîyarbekir: Weşanên Lîs, 2008.

Parıltı, Abidin. Dengbêjler Sözün Yazgısı, İstanbul: İthaki Yayınları, 2006. Poche, Christian. "Kürt Müziği”. Kürt Müziği, Danslart ve Şarkılart. Haz. Mehmet Bayrak. 1: 125-126. Ankara: Özge Yayınları, 2002.

Samur, Aziz. Destana Zembîlfiroş û Gulxatûn. İstanbul: Nûbihar Yayınları, 2015. 
Sokolov, Yuri M. Folklor: Tarih ve Kuram. wer. Yetke Özer. Ankara: Geleneksel Yayınlar1, 2009.

Tarduş, İbrahim. "Taybetiyên Lehengên Tradîsyonel di Vegotina Kurdî de”, The Journal of Mesopotamian Studies, 3/1, (Winter 2018), 57-76.

Uluçay, Ömer. Derwêşê Evdî Destanı. İstanbul: Do Yayınları, 2006.

Uzun, Mehmed. Dengbêjlerîm, İstanbul: İthaki Yayınları, 2006. 